\title{
RETRATOS MODERNISTAS DE OSCAR WILDE
}

\author{
Noel Rivas Bravo \\ Universidad de Sevilla
}

Oscar Wilde, como D'Annunzio, como Verlaine, fue un escritor admirado por los jóvenes modernistas de fin de siglo. José Martí, Enrique Gómez Carrillo, Rubén Darío y Manuel Machado tuvieron el privilegio, la dicha, de conocerlo personalmente. De las crónicas de esos encuentros literarios, que ellos mismos escribieron, recorto los impresionantes retratos del infortunado y exquisito dandy.

Antes conviene recordar el famoso principio de Horacio recogido en su Epístola a los Pisones: ut pictura poesis (la poesía es como la pintura). Y no se trata, como bien señala Esteban Torre, de encontrar en esa frase el fundamento de un paralelismo absoluto entre ambas formas de expresión artística, porque el medio expresivo de una obra de arte constituye y define su propia naturaleza ${ }^{1}$. Se trata, apropiándonos de ella en un sentido amplio, de que la literatura, el lenguaje poético, tiene la virtud, la capacidad de expresar, de copiar, la realidad. Es famosa la descripción del escudo de Aquiles en el canto XVIII de la Ilíada (vv. 483-608) y Dante, dice Alfonso Reyes, pinta los círculos del "Infierno" con la precisión de un topógrafo que usase palabras en vez de líneas ${ }^{2}$. Y ahí está el género del retrato, tan cultivado por los parnasianos, como una forma de caracterización de las cualidades físicas, morales y sicológicas de personajes reales o imaginarios. En el caso concreto de los retratos de Wilde, que nos legaron los modernistas, prevalece en ellos la estética de lo decadente entendida como transgresión de lo normal. Por medio de la comparación, la metáfora y las enumeraciones, Martí, Gómez Carrillo, Darío y Machado, nos trazan una imagen de Wilde elegante, refinada, sugestiva, culta, irónica, encantadora, pero no por eso ajena a un fondo de tristeza, soledad, dolor, desencanto y tragedia. No olvidemos que estos retratos reflejan además las dos etapas diferentes de su vida. Martí y Gómez Carrillo conocieron al poeta inglés rodeado de fama y gloria mientras que Darío y Machado lo conocieron pobre, menospreciado, enfermo, "al otro lado del jardín", como decía él mismo.

Fue José Martí el primero de los modernistas que conoció personalmente a Wilde. Martí residía entonces en Nueva York, adonde había llegado huyendo de su exilio español, para incorporarse, junto con otros patriotas cubanos, a las actividades revolucionarias independentistas. Martí era por aquellos días corresponsal del periódico La Opinión Nacional de Caracas. En una de sus crónicas fechada el 7 de enero de 1882 el poeta cubano informaba a sus lectores venezolanos de la reciente llegada de Wilde a Nueva York. Como

${ }^{1}$ E. Torre, Metapoiesis. Cuestiones de crítica literaria, Sevilla, Padilla Libros Editores \& Libreros, 2000, p. 87.

${ }^{2}$ A. Reyes, El deslinde. Prolegómenos a la teoría literaria, México, Fondo de Cultura Económica, 1983, p. 18. 
se sabe el poeta irlandés llegaba a la gran ciudad norteamericana invitado para impartir una serie de conferencias sobre el esteticismo inglés, que culminarían en una gira triunfal por Filadelfia, Washington, Baltimore y Boston. La prensa de Nueva York había preparado su visita destacando la singularidad de su personalidad, ofreciendo sus datos biográficos, publicando fragmentos de sus poemas y afirmando que Wilde personificaba el movimiento estético inglés. Lo cierto es que el admirable poeta llegó a Nueva York el 2 de enero de 1882 embarcado en el vapor Arizona y que fue tanta la curiosidad y el interés que despertó entre los periodistas que algunos de ellos alquilaron una lancha que los llevara abordo para entrevistarlo antes de pisar tierra. "Surgieron del mar" dijo Wilde pintorescamente. ¿Era Martí uno de aquellos periodistas? No lo sabemos, pero el retrato que nos dejó del poeta en la crónica arriba mencionada concuerda con las publicadas en los diarios y testimonios del momento. Oigámosla:

"Con los primeros días del año, llegó a Nueva York, a bordo de uno de esos vapores babilónicos, que parecen casas reales sobre el mar, un hombre joven y fornido, de elegante apostura, de enérgico rostro, de abundante cabello castaño, que se escapa de su gorra de piel sobre el Ulster recio que ampara del frío su robusto cuerpo. Tiene los ojos azules, como dando idea del cielo que ama, y lleva corbata azul, y sin ver que no está bien en las corbatas el color que está bien en los ojos. Son nuestros tiempos de corbata negra. Este joven lampiño, cuyo maxilar inferior, en señal de fuerza de voluntad, sobresale vigorosamente, es Oscar Wilde, el poeta joven de Inglaterra, el burlado y loado apóstol del estetismo"’3.

Una semana más tarde, el 9 de enero a las 8 de la noche, Oscar Wilde pronunciaba su primera conferencia en el Chickering Hall, casa de los lectores aristocráticos de Nueva York, con el título de The English Renaisance (El renacimiento inglés en el arte). El lleno de la sala era total, incluyendo gente de pie, y al finalizar la lectura el público aplaudió calurosamente. Martí era uno más de los espectadores. La crónica que escribió entonces sobre este acontecimiento lleva el sencillo título de Oscar Wilde y en ella resume con algunos pormenores y citas textuales el tema de la conferencia sobre la historia y los ideales del esteticismo inglés, aunque no deja de observar, consecuente con su ideología política, que "no tuvo esa lectura aquella profunda mira y dilatado alcance que placerían a un pensador". Martí registra además en esta crónica un dato curioso para los historiadores del modernismo en hispanoamérica cuando afirma que "es cierto que en nuestras tierras luminosas y fragantes tenemos como verdades trascendentales esas que ahora se predican a los sajones como reformas sorprendentes y atrevidas". Pero uno de los detalles más interesante de la crónica es la descripción minuciosa que hace de la figura de Wilde vestido con el atuendo estético del dandy por excelencia:

"El cabello le cuelga cual el de los caballeros de Elizabeth de Inglaterra, sobre el cuello y los hombros; el abundoso cabello, partido por esmerada raya hacia la mitad de la frente. Lleva frac negro, chaleco de seda blanco, calzón corto y holgado, medias largas de seda negra, y zapatos de hebilla. El cuello de su camisa es bajo, como el de Byron, sujeto por caudalosa

\footnotetext{
${ }^{3}$ J. Martí, "Escenas Norteamericanas", en Obras completas, t. 9, La Habana, Editorial de Ciencias Sociales, 1975, pág. 221.
} 
corbata de seda blanca, anudada con abandono. En la resplandeciente pechera luce un botón de brillantes, y del chaleco le cuelga una artística leopoldina" ${ }^{4}$.

También Enrique Gómez Carrillo conoció personalmente a Wilde. En realidad fue el único de los modernistas que llegó a ser su verdadero amigo y confidente. Las crónicas de sus. encuentros está recogida en algunos capítulos de su obra En plena bohemia ${ }^{5}$. Allí se nos da cuenta del primer día en que ambos se conocieron en la célebre tertulia que tenía los sábados en sus salones de la rue du Bac el distinguido poeta nortemericano Stuart Merril. Era una tarde de finales del año 1891, Gómez Carrillo tenía apenas 18 años de edad, había llegado a París pensionado por el gobierno guatemalteco para dedicarse a la carrera de periodista y era el niño mimado de los poetas y escritores del momento. Wilde, que todavía no era un personaje de leyenda, era aclamado y celebrado en las famosas tertulias y círculos literarios del París finisecular. Le great event des salons littéraires parisiennes, dijo de él un reportero de $L$ 'Écho de París. Parece que desde el primer momento se despertó entre Gómez Carrillo y Wilde una especial simpatía, porque llegaron a ser tan íntimos amigos que circularon ciertos rumores que los relacionaban más allá del aprecio personal y literario. La verdad es que Gómez Carrillo mantuvo su buena amistad con Wilde hasta poco antes de morir éste y aprovechó todas sus visitas a París, para encontrase con él. En este primer encuentro, Gómez Carrillo, que ni siquiera había oído mencionar el nombre de Wilde, se sintió "atraído por su estampa gigantesca, su sonrisa de dientes muy largos y por su mirada de ojos muy húmedos." Pero más que un diálogo o una conversación entre ambos lo que se produjo fue un interrogatorio de Wilde a Gómez Carrillo sobre su edad, su origen, su relación con Verlaine, su gusto por las mujeres y otros temas de interés cuyas respuestas le hacían decir frases entre irónicas y admirativas. Oigamos la caracterización que hace Gómez Carrillo de la personalidad del poeta irlandés y de su "palabra lenta y musical":

"Hablando así, con una voz extraña en la que cantaba toda una gama de notas suaves y agudas, voz muy inglesa y llena de contrastes, algo cómicos, Wilde pasábase las manos por el rostro, como deseando modelarse a sí mismo según el canon de la belleza masculina. Y yo pensaba: Este hombre sufre de no ser guapo. Porque, la verdad sea dicha, aquel primer día, parecióme agradable, fino, interesante, elegante; pero guapo, no. La sonrisa de sus labios blandos y sinuosos, descubría a cada minuto una dentadura enorme y gris, con adornos áureos. Sus mejillas, ya un poco pesadas, eran de un rosado que se acercaba a lo cárdeno. Su cabellera, lisa y luciente, hacía a su rostro enorme un marco rubio que me chocaba por lo femenino, o mejor dicho, por lo afeminado de sus bandeaux. Sólo sus ojos, muy tiernos, muy húmedos, muy claros, engarzados cual dos esmeraldas de Siberia en los párpados abotagados, tenían una expresión que podía revelar al poeta. En suma: era un inglés apoplético, igual a muchos ingleses que, lejos de parecernos bellos, se nos antojan un poco grotescos. ¿Cómo, pues, iba yo a adivinar sus pretensiones de Narciso?... Más tarde no sólo me dí cuenta de que se creía hermoso, sino que hasta llegué a comprender que tenía más vanidad como beau garçon que como gran poeta. También en calidad de dandy mostrábase orgulloso. Bastaba verlo para notar su extremada coquetería suntuaria, su cuidado en el vestirse, su arte en el

${ }^{4}$ J.Martí, “Crítica y Arte”, en Ídem, t. 15, p. 360.

${ }^{5}$ E. Gómez Carrillo, En plena bohemia. Treinta años de mi vida, Libro $2^{o}$, en Obras completas, $t$. 16, Madrid, Mundo Latino, s/f (1919). Se ha publicado recientemente con ed. y prol. de José Luis García Martín, Gijón, Llibros del Pexe, 1999. 
choix de las corbatas, de los guantes, de los pañuelos. "El Wilde que yo conocí- dice Lord Douglas- consistía en un sombrero de copa luciente, en una levita impecable, en un pantalón a rayas y en par de botines de charol. Agregad un bastón con puño de oro y un par de guantes de Suecia gris; tal era el hombre." Así lo vi yo, en efecto, aquella tarde de 1891"6.

No olvida Gómez Carrillo de transcribir algunos de los famosos "poemas hablados" de Wilde, como el de "La casa del juicio" y el "Hacedor del bien", recogidos más tarde en sus Poemas en prosa, ni de ofrecernos información valiosísima y de primera mano sobre la gestación y concepción de Salomé, que, como se sabe, fue escrita en Francia y en francés?.

También Rubén Darío conoció a Oscar Wilde. El encuentro entre ambos artistas de la palabra se produjo en la primavera del año 1900 en el bar Calisaya en París, lugar muy visitado por los jóvenes escritores de la época y famoso por los 132 cocteles de su repertorio. Darío había llegado por segunda vez a esta ciudad enviado por el diario $L a$ Nación de Buenos Aires, para escribir sus reportajes sobre la Exposición Universal entonces en plena celebración. Y fue precisamente el guatemalteco Enrique Gómez Carrillo y el escritor francés Ernesto Lajeneuse, quienes se lo presentaron. Hacía casi tres años que el autor de Salomé había abandonado la cárcel y vivía refugiado en París, pobre y olvidado, en el hotel d'Alsace, rue des Beaux-Arts, con el significativo nombre balzaciano de Sebastian Melmoth. En la crónica "Las purificaciones de la piedad", recogida en Peregrinaciones $^{8}$, escrita el 8 de diciembre de 1900, ocho días después del fallecimiento de Wilde, Darío recordaría los detalles de este singular encuentro y nos dejaría un retrato impresionante del esteta irlandés.

“... un hombre de aspecto abacial, un poco obeso, con aire de perfecta distinción y cuyo acento revelaba en seguida su origen inglés. En la conversación su habilidad de decidor se marcaba de singular manera. Siempre trataba asuntos altos, ideas puras, cuestiones de belleza. $\mathrm{Su}$ vocabulario era pintoresco, fino y sutil. Parecía mentira que aquel gentleman absolutamente correcto fuese el predilecto de la Ignominia y el revenant de un infierno carcelario"'.

Sin duda para Darío tuvo una especial importancia conocer personalmente a Wilde, porque años más tarde el recuerdo de este encuentro lo registraría de nuevo con mayor precisión en sus breves apuntes autobiográficos:

"Había un bar en los grandes bulevares que se llamaba Calisaya. Carrillo y su amigo Ernesto Lajeneuse me presentaron allí a un caballero un tanto robusto, afeitado, con algo de abacial, muy fino de trato y que hablaba el francés con marcado acento de ultratumba. Era el gran

\footnotetext{
${ }^{6}$ Ídem, pp. 190-192.

${ }^{7}$ Ídem, pp. 195-220.

${ }^{8}$ R. Darío, Peregrinaciones, pról. de Justo Sierra, París, Librería de la Vda. de CH. Bouret, 1910.

${ }^{9}$ Ídem, p. 125.
} 
poeta desgraciado Oscar Wilde. Rara vez he encontrado una distinción mayor, una cultura más elegante y una urbanidad más gentil"10.

En la crónica antes mencionada, Darío hace gala de un conocimiento a fondo del genio y la vida de Wilde, nos habla de su fama y de su gloria, de su actitud crítica y burlona frente a la burguesía, -"el querer a toda costa épater les burgeois"- del escándalo y la vergüenza del proceso que lo llevó a la cárcel y que puso al desnudo la hipocresía de la sociedad inglesa, de la cobardía e ingratitud de sus amigos, que lo abandonaron en los momentos más difíciles, y el mérito artístico eminente de su obra. "Su cerebración- dice Darío- es para sibaritas de ideología", subrayando la inclinación de Wilde por las ideas atrevidas y su culto a la belleza. Especial admiración le merece a Rubén la obra narrativa de Wilde, como el Dorian Gray, donde reconoce la influencia de Huysmans y su $A$ rebours, sus ensayos, como Intentions, nutridos de erudición, habilidad verbal y deliciosas paradojas, su obra dramática, como A woman of no importance, Lady Windemere's fan y Salomé, que tanta repercusión tuvieron entre el público inglés y francés de fin de siglo. Sin embargo, para Darío, en contradicción con la opinión de hoy, no son las páginas de crítica y de estética de Wilde lo más perdurable de toda su obra, sino su poesía: "A mi entender, -dijo- lo preferible en la obra de ese poeta maldito, de ese admirable infeliz, son sus poemas, poemas en verso y poemas en prosa, en los cuales la estética inglesa cuenta muy rica joyas". Finaliza la crónica de nuestro poeta augurando, con un noble sentido de la justicia poética y de la fe cristiana, la gloria y el renacer de la personalidad de Wilde cuando "venga la primavera de Dios, en la purificación de la Tierra".

Y también Manuel Machado conoció personalmente a Oscar Wilde. Y también fue el bar Calisaya, en el año de 1898, el escenario del primer encuentro. Machado trabajaba entonces como traductor de la Casa Garnier Hermanos y era asiduo visitante del famoso bar donde se reunía con Laurent Taillade, Jean Moréas, Paul Fort, Enrique Gómez Carrillo -su buen amigo-, Rubén Darío de quien fue secretario y Luis Bonnafoux. - "Mi vida fue plenamente la que llevaban allí los estudiantes y los artistas jóvenes del mundo entero", recordaba años después. En la hermosa crónica "La última balada de Oscar Wilde", recogida en su obra El Amor y la Muerte ${ }^{11}$, Machado se quejaba de la ingratitud e indiferencia de la intelectualidad francesa con el célebre escritor al que en los días de la presentación de Salomé (febrero de 1896) había aclamado gloriosamente. Wilde no era entonces el artista deslumbrante y encantador sino un hombre pobre, víctima de su pasado, ajeno a los salones de actualidad y reuniones de moda, que habían sido antes el escenario de sus admirables conversaciones. En el retrato del esteta que nos dejó Machado en esta crónica se vislumbra el terrible cambio que había sufrido su gran personalidad después de abandonar la cárcel de Reading un año antes:

${ }^{10}$ R. Darío, Autobiografía, en Obras completas, Madrid, Afrodisio Aguado, 1950, p. 473.

${ }^{11}$ M. Machado, "La última balada de Óscar Wilde" en José Luis Ortiz de Lanzagorta (ed.), Prosa. El amor y la muerte. Día por día de mi calendario, Sevilla, Universidad, 1974, pp. 37-45. 
"Canoso y algo encorvado, con mengua de su gran talla, el arrogante Oscar se había convertido en un dulce personaje sin desplantes ni pose. Un poco triste, un poco irónico...; vulgar, no llegó a serlo nunca, pero había dejado de ser teatra"12.

Sin embargo, a pesar de su lamentable estado Wilde no había dejado de ser el artista que cautivaba con el don de su encantadora conversación. Y así, "en voz baja y mimosa, lentamente, hablando en muy buen francés, con un acento británico marcadísimo que hacía suspirar los finales de los párrafos", pudo contarle a Machado y a Moréas la singular historia de una sortija de oro con una gran piedra verde que llevaba en su dedo meñique. Según Wilde, el primer dueño de esta sortija había sido un rajá de la India que murió asesinado por sus compatriotas ingleses y que luego él heredó de uno de sus hijos. Y, como buen amante de las parábolas dijo, justificado su propio destino y dándole vueltas a la historia, que el que poseyera la joya sería siempre un desgraciado sin que pudiera librarse de ello a menos que la perdiera en contra de su propia voluntad.

Luego, Machado nos relata su última visita Wilde dos días antes de su muerte. Permitásenos transcribir íntegramente, a pesar de su extensión, la escena y el comentario con que culmina la crónica, porque ponen al desnudo la singular personalidad de Wilde, que ni siquiera unos días antes de fallecer dejó de mezclar en su conversación el arte la vida y el humor:

"Entramos en la alcoba, modesta habitación amueblada a lo imperio. Un pesado lecho de Caoba con cortinas rojas.

Óscar nos tendió la mano sonriendo. Pero una mano que abrasaba.

-No me agrada dar disgustos a los amigos, ni molestias a los indiferentes. Además, esto no es nada. Ahora voy a estar mejor que nunca, porque -añadió, dirigiéndose a mí-, ¿se acuerda usted de la famosa sortija?... Pues bien...la he... se ha perdido definitivamente, ha desaparecido, se fue. De modo que ya voy a ser completamente feliz.

Dos días después, un jovencito inglés que comía en mi restaurant, decía a sus compañeros de mesa:

-Hemos perdido a un altísimo poeta. El célebre Oscar Wilde ha muerto ayer a consecuencia de una meningitis.

-¿Lo perdonará ahora Inglaterra?

$-\mathrm{No}^{\prime 13}$.

Sí, lo perdonó. En el año de 1995, un brumoso día de mayo, fue homenajeado y reivindicado oficialmente por el gobierno, la corona y el pueblo inglés, con una placa en el Rincón de los Poetas de la Abadía de Westminster y, en esa ocasión, Oscar Merlin Holland Wilde, nieto de nuestro poeta, recibió las disculpas públicas de los descendientes del

\footnotetext{
12 Ídem, p. 38

${ }^{13}$ Ídem, p. 45.
} 
marqués de Queensberry. Su consagración definitiva nos ha llegado de la pluma de Borges quien dijo que Wilde siempre tenía razón y que sus obras parecen haber sido escritas esta mañana. 



\section{NORMAS DE PUBLICACIÓN}

1. Los originales deberán ser inéditos y no estar aprobados para su publicación por ninguna otra entidad.

2. Los originales recibidos serán examinados por miembros del Consejo de Redacción y/o del Consejo Asesor de la Revista.

3. La publicación de trabajos en Philologia Hispalensis no da derecho a remuneración alguna. Los derechos de edición son de la Facultad de Filología de la Universidad de Sevilla y es necesario su permiso para cualquier reproducción. En todo caso, será preciso citar la procedencia en cualquier reproducción parcial o total.

4. Los autores tendrán derecho a veinte separatas de los artículos y tres de las reseña.

\section{NORMAS DE PRESENTACIÓN}

1. Los originales definitivos se enviarán al Secretario de la revista (Facultad de Filología, C/ Palos de la Frontera, s/n, 41004 Sevilla). Irán precedidos de una hoja en la que figurará el título del artículo, el nombre del autor (o autores), dirección postal y electrónica, teléfono y nombre de la institución a la que pertenece. Asimismo, se hará constar la fecha de envío del trabajo.

2. Los artículos y notas tendrán una extensión máxima de veinticinco y ocho páginas respectivamente, compuestas según las características de la Plantilla inserta a tal efecto en la página web de la Facultad (www.siff.us.es). Las reseñas tendrán una extensión máxima de cinco páginas. En todo caso, el Consejo de Redacción se reserva el derecho de proponer al autor la inclusión de su trabajo en una sección distinta de la indicada.

3. Se enviarán dos copias impresas de cada manuscrito. Debe adjuntarse una copia del documento original definitivo en soporte informático. Sólo se aceptarán disquetes de 3'5 pulgadas formateados en sistema MS-DOS. Sólo se aceptarán ficheros creados con el programa MS WORD, todas ellas en versión Windows, debiendo llevar las notas a pie de página enumeradas consecutivamente. Los cuadros, mapas, gráficos, tablas, figuras, etc., que se entreguen con los trabajos deberán ser originales y se presentarán en formato Word.

4. Cada artículo irá acompañado de un resumen en inglés y en español de no más de quince líneas (aprox. 250 palabras), conforme a las normas de la plantilla antes citada.

\section{NORMALIZACIÓN DE CITAS Y NOTAS}

1. Los números indicativos de nota serán numerales arábigos, escritos ligeramente por encima de la línea de escritura, e inmediatamente después del material al que se refiere. No irán entre paréntesis.

2. Si la referencia es breve, puede insertarse entre paréntesis en el texto (Ej. Eliot 1999: 37), pero la primera referencia completa de un trabajo debe aparecer en una nota o al final del trabajo. 
3. Las citas bibliográficas, ajustadas siempre a la plantilla, atenderán a las normas siguientes:

LIBROS: INICIAL., APELLIDO DEL AUTOR, TÍTULO (CIUDAD, EDITORIAL, AÑO) PÁGINAS

T. S. Eliot, Función de la poesía y función de la crítica, Barcelona, Tusquets, 1999, pp. 1416.

REVISTAS: INICIAL., APELLIDO DEL AUTOR, "TÍTULO DEL ARTÍCULO", REVISTA, N (AÑO), PÁGINAS

Ejemplo: A. Díaz Tejera, "El género en griego clásico: descripción sincrónica y explicación diacrónica", Revista Española de Lingüística, 11 (1981), pp. 13-31.

4. Las citas de Internet atenderán a las normas siguientes:

INICIAL, APELLIDO DEL AUTOR, TÍTULO DEL ARTÍCULO, Título de la página web. Editor o autor de la página de Internet. Fecha de consulta de la página. <Dirección URL de la página>

Ejemplo: Sarah Kline, "Bringing up Jo: Little Women and the American Nineteenth Century Conduct Book Tradition>". Domestic Goddesses. Editora Kim Wells. Internet. 13-11-01. <http://www.womenwriters.net/domesticgoddess/kleinalcott.htm> 


\title{
PHILOLOGIA HISPALENSIS BOLETÍN DE SUSCRIPCIÓN
}

Nombre

Dirección

C.P. Población

Ciudad

País

C.I.F. (España) Teléfono

E-mail Fecha

Firma

Suscripciones (2 números anuales):

España, $18 €$. Otros países, $24 €$ (I.V.A. incluido)

Número suelto: $12 €$

Precio especial suscripción: $\square$ + volúmenes I-IX (10 fascículos) $60 €$ El pago puede efectuarse mediante:

$\square$ transferencia bancaria a

Entidad: 2098 (Monte de Piedad)

Sucursal: 0028 (Plaza Villasís, nº 1, 41001 - Sevilla)

Dígito control: 04

Cuenta corriente: 0104302113

contra reembolso del primer envío

$\square$ giro postal

Envíese a

\author{
SECRETARIADO DE PUBLICACIONES \\ UNIVERSIDAD DE SEVILLA \\ Porvenir, 27 \\ 41013 - Sevilla \\ (Tel. 95 - 44874 47; fax. 95 - 44874 43)
}




